\title{
Gérmen com pericarpo de milho desengordurado na formulação de biscoitos tipo cookie
}

\author{
Use of defatted corn germ with pericarp in cookie formulation
}

\author{
Luciana de Oliveira Froes ${ }^{\mathrm{I}}$ Maria Amélia Oliveira Falqueto ${ }^{\mathrm{II}}$ Maiza Vieira Leão de Castro \\ Maria Margareth Veloso Naves ${ }^{\text {II }}$
}

\section{RESUMO}

O gérmen com pericarpo, subproduto do processamento do grão de milho, possui alto valor nutricional, porém é pouco aproveitado na alimentação humana. Os objetivos deste estudo foram caracterizar quimicamente o gérmen com pericarpo de milho desengordurado (GMD), desenvolver formulações, avaliar a aceitabilidade e analisar a composição centesimal de biscoitos tipo cookie contendo GMD. Foi determinada a composição centesimal do GMD e dos biscoitos, e analisados o conteúdo de minerais e o escore de aminoácidos essenciais (EAE) do GMD, conforme metodologias padronizadas na literatura. Foram formulados biscoitos com 0\% (biscoito controle), 50\% (B50) e 100\% (B100) de substituição de farelo de aveia por GMD. Para a análise sensorial, utilizou-se escala hedônica de nove pontos.

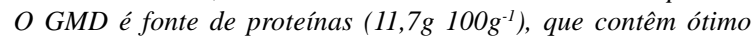
perfil de aminoácidos $(E A E=1,26)$ e é rico em fibra alimentar $\left(28,9 \mathrm{~g} 100 \mathrm{~g}^{-1}\right)$, ferro e zinco $\left(5 \mathrm{mg} 100 \mathrm{~g}^{-1}\right)$. Todos os biscoitos foram aceitos sensorialmente (aceitação global e aparência), sendo o biscoito $B 50$ mais aceito que o B100. Os biscoitos com GMD são fonte de proteínas $\left(12,5 \mathrm{~g} 100 \mathrm{~g}^{-1}\right)$ e contêm alto teor de fibras alimentares $\left(10,0 \mathrm{~g} 100 \mathrm{~g}^{-1}\right)$. O emprego do GMD na formulação de alimentos à base de cereais elevou o valor nutricional desses produtos, podendo agregar valor a este subproduto da indústria de milho.

Palavras-chave: subproduto de milho, valor nutritivo, análise sensorial, composição química.

\section{ABSTRACT}

The germ with pericarp, byproduct of corn grain processing, has a high nutritional value, but is little used in food. Our objectives were to analyze the chemical composition of the defatted corn germ with pericarp (DCG) and to develop

\begin{abstract}
formulations, to evaluate the acceptability and to analyze the chemical composition of cookies with DCG. The proximal composition of DCG and of cookies was determined, and the mineral content and the essential amino acid score (EAE) were analyzed in DCG, according to standard methods of the literature. Cookies with 0\% (control), 50\% (B50) and 100\% (B100) of replacement of oat bran for DCG were formulated. The sensory analysis was performed by using hedonic scale of nine points. The DCG is source of protein $\left(11.7{\left.\mathrm{~g} 100 \mathrm{~g}^{-1}\right) \text { with }}\right.$ optimal amino acid profile $(E A E=1.26)$, and it is rich in dietary fiber $\left(28.9 \mathrm{~g} 100 \mathrm{~g}^{-1}\right)$, iron and zinc $\left(5 \mathrm{mg} 100 \mathrm{~g}^{-1}\right)$. All cookies were sensorially accepted (overall acceptance and appearance), and the cookie B50 was more accepted than the B100. The

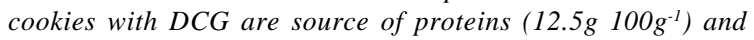

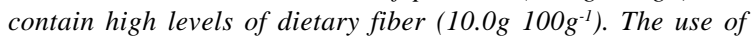
DCG in the formulation of the based-cereal foods increased the nutritional value of these products and can to add value to this byproduct of the corn grain processing.
\end{abstract}

Key words: corn byproduct, nutritive value, sensory analysis, chemical composition.

\section{INTRODUÇÃO}

O milho é produzido em quase todos os continentes, sendo sua importância econômica caracterizada por suas diversas formas de utilização, que vão desde a alimentação humana até a indústria de alta tecnologia. O Brasil é o terceiro maior país produtor de milho, com produção total estimada em 52,5 milhões de toneladas, para a safra 2010/2011 (CONAB, 2010). Grande parte da produção de milho (em torno de 85\%)

IPrograma de Pós-graduação e Ciência e Tecnologia de Alimentos, Escola de Agronomia e Engenharia de Alimentos, Universidade Federal de Goiás (UFG), Campus Samambaia, Rodovia Goiânia/Nova Veneza, km 0, 74690-900, Goiânia, GO, Brasil. E-mail: lu@froes.org.

"Faculdade de Nutrição, UFG, Goiânia, GO, Brasil 
é destinada à alimentação animal, enquanto apenas $4 \%$ do milho produzido são consumidos diretamente na alimentação humana, e 10\% são utilizados pela indústria alimentícia em diversos produtos (WATSON \& RAMSTED, 1999).

O grão de milho é composto por ponta, endosperma, pericarpo e gérmen. Essas estruturas se diferem em relação à composição química e podem ser separadas por processamento industrial, pelo método de moagem a seco (WATSON \& RAMSTED, 1999). No processo de degerminação, obtém-se uma fração única contendo gérmen e pericarpo, que representa $11 \%$ do grão de milho. Esta fração possui teores elevados de lipídios, proteínas de boa qualidade nutricional (NAVES et al., 2011), fibras alimentares e minerais, sendo muito utilizada na formulação de ração animal (CASTRO et al., 2009; HERNANDEZ et al., 1999).

O gérmen contém $83 \%$ do total de lipídios do grão de milho e é considerado fonte de óleo de alta qualidade (WATSON \& RAMSTED, 1999). Na indústria, a fração gérmen com pericarpo é usada em larga escala como matéria-prima para a extração de óleo, gerando um subproduto desengordurado de baixo valor agregado para a indústria moageira, o gérmen com pericarpo de milho desengordurado (GMD). O uso do GMD na indústria alimentícia, como em biscoitos tipo cookie, pode ser uma alternativa para agregar valor a esta matéria-prima e mais uma opção para melhorar a qualidade nutricional de biscoitos, como ingrediente-fonte de proteínas, fibras e minerais (CASTRO et al., 2009).

O elevado teor de fibras alimentares do GMD

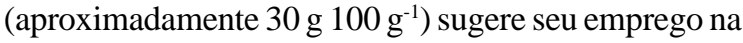
formulação de biscoitos, em substituição a ingredientes tradicionalmente usados como fonte de fibra, a exemplo do farelo de aveia, que contém cerca de $20 \%$ deste nutriente (GRANSTEN et al., 2002). Outro alimento rico em fibras é a castanha de baru torrada (13g $\left.100 \mathrm{~g}^{-1}\right)$, que pode ser utilizada na elaboração de biscoitos, contribuindo assim para o aproveitamento dos frutos do Cerrado (SOARES JÚNIOR et al., 2010).

A composição química do GMD e a busca por alimentos mais nutritivos e saudáveis justificam pesquisas sobre seu emprego na alimentação humana. Dessa forma, os objetivos deste estudo foram caracterizar quimicamente o GMD, desenvolver biscoitos tipo cookie contendo GMD e analisar a aceitabilidade e a composição centesimal dos biscoitos elaborados.

\section{MATERIAL E MÉTODOS}

Obtenção, processamento e análise microbiológica da amostra de GMD
O GMD testado foi produzido pela indústria Caramuru Alimentos Ltda., conforme descrito na figura 1. A amostra de GMD foi submetida à análise dos seguintes microrganismos: coliformes a $45^{\circ} \mathrm{C}$, Bacillus cereus, Estafilococos coagulase positiva e Salmonella sp em 25g (APHA, 2001; BRASIL, 2001).

\section{Análises químicas do GMD}

Para a determinação da composição centesimal, os teores proteicos foram obtidos por meio da análise de nitrogênio total e conversão em proteína bruta (fator de conversão - 6,25), segundo o método semimicro de Kjeldahl (AOAC, 1990). Foram analisados os teores de umidade e de cinzas, conforme o INSTITUTO ADOLFO LUTZ (2005), de fibra alimentar total (solúvel e insolúvel), de acordo com PROSKY et al. (1988), e de lipídios totais, segundo BLIGH \& DYER (1959). Os carboidratos foram estimados por diferença, subtraindo-se de 100 os valores obtidos de umidade, proteína, lipídios, cinzas e fibra alimentar total. O valor energético total dos produtos formulados foi estimado utilizando-se os fatores para conversão de $4 \mathrm{kcal} \mathrm{g}^{-1}$ para proteínas e carboidratos e $9 \mathrm{kcal} \mathrm{g}^{-1}$ para lipídios (MERRIL \& WATT, 1973).

O perfil de aminoácidos foi determinado nas amostras hidrolisadas, que foram injetadas em analisador automático de aminoácidos para a detecção e quantificação por colorimetria (ALONZO \& HIRS, 1968). A partir dos resultados desta análise, foi estimado o escore de aminoácidos essenciais (EAE), de acordo com o padrão de necessidade preconizado pela Organização Mundial de Saúde (WHO, 2007). O cálculo foi feito conforme a equação: $\mathrm{EAE}=$ (mg do aminoácido em $1 \mathrm{~g}$ de proteína teste/mg do aminoácido no padrão de necessidade) x 100 .

Os minerais (cálcio, ferro e zinco) foram quantificados por meio de espectrofotometria de absorção atômica (espectrofômetro Varian, modelo SpectrAA-200), utilizando-se os parâmetros instrumentais específicos para cada nutriente (AOAC, 1990).

\section{Elaboração dos biscoitos tipo cookie}

Os biscoitos foram elaborados de acordo com as formulações descritas na tabela 1 e processados conforme figura 1. A formulação do biscoito tipo cookie controle (BC) foi desenvolvida a partir de testes preliminares com receitas caseiras. Para avaliar a contribuição do GMD no valor nutricional e sensorial dos biscoitos, foram preparadas formulações de biscoitos com proporções de $0 \%$ (controle), 50\% (B50) e 100\% (B100) de substituição de farelo de aveia por GMD. 


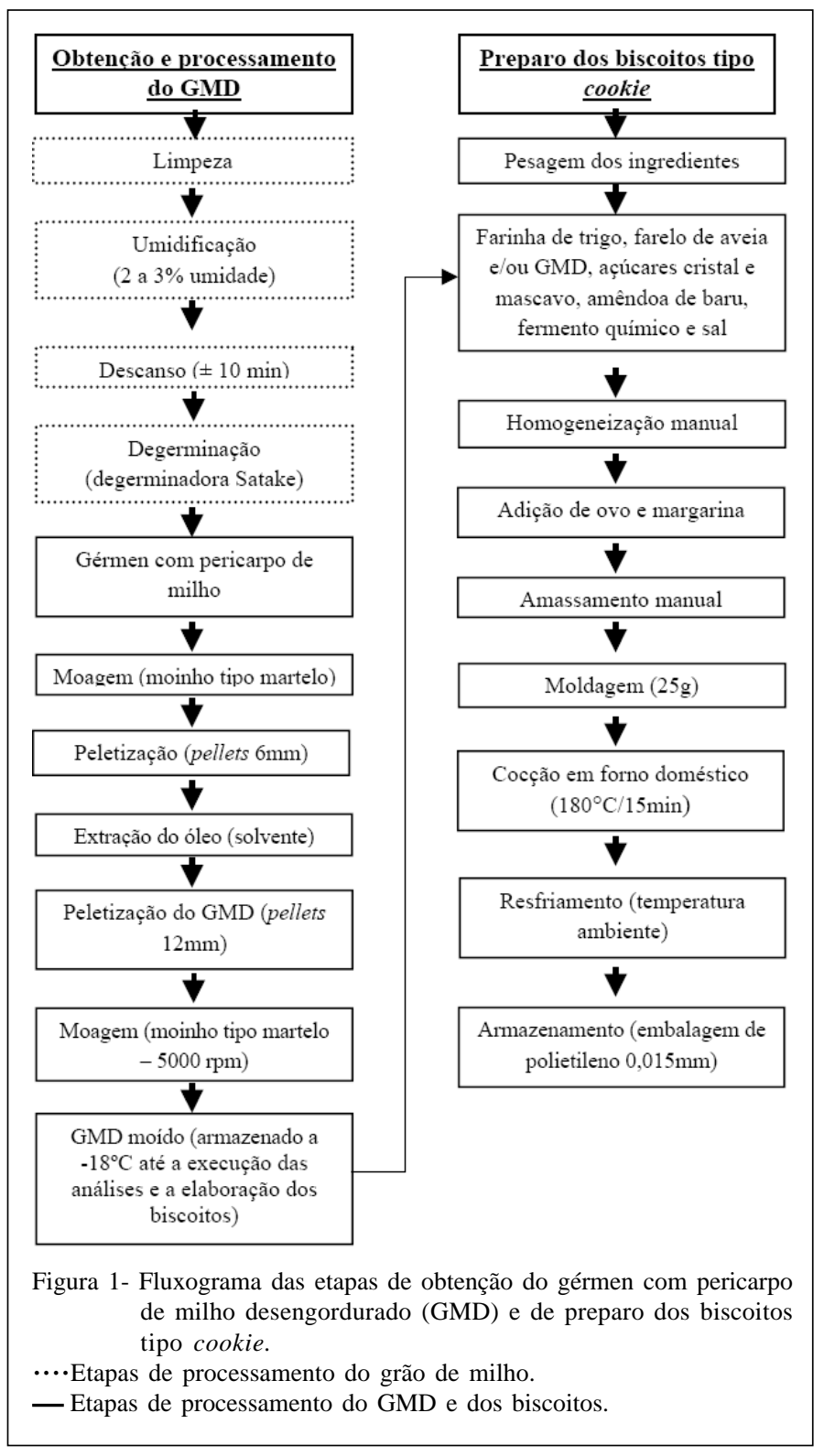

Análises sensorial e química dos biscoitos

A análise sensorial foi conduzida por meio dos testes de aceitação global (aroma, sabor e textura) e de aparência dos biscoitos, utilizando-se escala hedônica estruturada de nove pontos (1, que representa desgostei muitíssimo e 9, gostei muitíssimo) (STONE \& SIDEL, 1985). A análise sensorial foi realizada por 48 provadores não treinados, adultos, de ambos os sexos, representados por consumidores potenciais do produto dentre professores, funcionários e alunos da Faculdade de Nutrição/UFG. Para participar da pesquisa, todos os provadores assinaram o Termo de Consentimento Livre e Esclarecido, aprovado pelo
Comitê de Ética em Pesquisa da UFG (Protocolo COEP no 182/2009). As amostras dos biscoitos foram apresentadas codificadas com três dígitos, em pratos descartáveis brancos, e servidas em cabines individuais iluminadas com luz vermelha, para o teste de aceitação global, e com luz fluorescente, para análise da aparência. Os biscoitos aceitos sensorialmente foram analisados quanto à composição centesimal, conforme metodologias descritas para o GMD.

Análise estatística

Os resultados foram expressos na forma de média e desvio-padrão e foram submetidos à análise 
Tabela 1 - Quantidade (\% e total) dos ingredientes de biscoitos elaborados com diferentes teores de gérmen de milho desengordurado (GMD).

\begin{tabular}{|c|c|c|c|c|}
\hline \multirow{3}{*}{ Ingrediente } & \multirow{3}{*}{ Formulação básica (\%) } & \multicolumn{3}{|c|}{----Biscoito* (g) } \\
\hline & & & & \\
\hline & & $\mathrm{BC}$ & B50 & B100 \\
\hline Farinha de trigo & 21,3 & 160 & 160 & 160 \\
\hline Farelo de aveia & $14,7^{* *}$ & 110 & 55 & 0 \\
\hline GMD & $0,0^{* *}$ & 0 & 55 & 110 \\
\hline Açúcar cristal & 14,7 & 110 & 110 & 110 \\
\hline Açúcar mascavo & 12,0 & 90 & 90 & 90 \\
\hline Farinha de castanha de baru & 6,7 & 50 & 50 & 50 \\
\hline Castanha de baru picada & 6,7 & 50 & 50 & 50 \\
\hline Fermento em pó & 0,7 & 5 & 5 & 5 \\
\hline Ovo & 15,2 & 115 & 115 & 115 \\
\hline Margarina & 8,0 & 60 & 60 & 60 \\
\hline TOTAL & 100,0 & 750 & 750 & 750 \\
\hline
\end{tabular}

* BC: biscoito tipo cookie controle (0\% de GMD); B50: biscoito tipo cookie com 50\% de substituição do farelo de aveia por GMD; B100: biscoito tipo cookie com $100 \%$ de substituição do farelo de aveia por GMD.

\% de farelo de aveia e GMD no B50 é de 7,35\% cada e, no biscoito B100, é de 0\% e 14,7\%, respectivamente.

de variância (ANOVA) e teste de comparação de médias (Tukey, 5\% de probabilidade). As análises estatísticas foram realizadas usando o programa Statistica (STATSOFT, 2004).

\section{RESULTADOS E DISCUSSÃO}

Gérmen com pericarpo de milho desengordurado

As análises microbiológicas para coliformes a $45^{\circ} \mathrm{C}$, Bacillus cereus, Estafilococos coagulase positiva e Salmonella sp, resultaram em valores abaixo dos limites máximos permitidos (BRASIL, 2001), indicando segurança higiênico-sanitária da amostra de GMD para uso na alimentação humana. O GMD (Tabela 2) apresentou teor de proteína similar ao relatado para

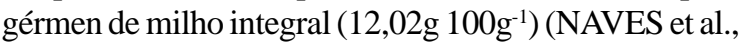
2011) e para gérmen de milho desengordurado (12,71g $100 \mathrm{~g}^{-1}$ ) (HERNANDEZ et al., 1999). Em relação ao teor de fibra alimentar, o GMD pode ser considerado como matéria-prima com alto teor de fibra (BRASIL, 1998), sendo o valor encontrado no presente estudo (28,9g $\left.100 \mathrm{~g}^{-1}\right)$ próximo ao relatado por NAVES et al. (2011), para gérmen de milho integral $\left(27,8 \mathrm{~g} 100 \mathrm{~g}^{-1}\right)$. O conteúdo de fibra do GMD foi superior ao encontrado por GRASTEN et al. (2002), em farelo de aveia e em farelo de arroz extrusado (18g $100 \mathrm{~g}^{-1}$ e $16 \mathrm{~g} 100 \mathrm{~g}^{-1}$, respectivamente), e menor que em farelo de trigo (43g $\left.100 \mathrm{~g}^{-1}\right)$.

O GMD apresentou concentrações de todos os aminoácidos essenciais acima do padrão de necessidade (WHO, 2007), como mostrado na tabela 2 , destacando-se o teor elevado de lisina, aminoácido limitante da proteína do milho (NAVES et al., 2011). O EAE foi de 1,26 (26\% superior ao padrão), o que confirma o bom perfil de aminoácidos da proteína do GMD. Considerando que a qualidade da proteína de um alimento pode ser estimada pelo seu perfil de aminoácidos essenciais e sua digestibilidade (WHO, 2007), e que o gérmen com pericarpo de milho possui boa digestibilidade e qualidade proteica (NAVES et al., 2011), espera-se que a proteína do GMD, que difere do gérmen com pericarpo de milho somente pelo teor de lipídios, seja também de boa qualidade nutricional.

Em relação à composição em minerais (Tabela 2), o GMD pode ser considerado rico em ferro

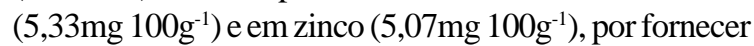
mais de $30 \%$ da recomendação desses nutrientes (48\% e 46\%, respectivamente) em $100 \mathrm{~g}$ de alimento sólido (BRASIL, 1998). O valor recomendado desses minerais é de 11mg, para indivíduos adultos (IOM, 2001).

\section{Biscoitos tipo cookie com GMD}

Todas as formulações foram aceitas sensorialmente (escores superiores a 6) quanto à avaliação global e aparência (Tabela 3). A formulação com 50\% de substituição do farelo de aveia por GMD (B50) apresentou a maior média para avaliação global, com diferença significativa $(\mathrm{P}<0,05)$ em relação ao biscoito B100, sendo esta média superior ao valor relatado para biscoitos contendo gérmen de milho integral (CASTRO et al., 2011). Os escores médios atribuídos à aparência foram superiores a 6,5 e maiores que o obtido por CASTRO et al. (2011), de 5,87. Ressalta-se que mais de $90 \%$ dos provadores atribuíram 
Tabela 2 - Composição química do gérmen com pericarpo de milho desengordurado (GMD) e de biscoitos tipo cookie elaborados com GMD.

\begin{tabular}{|c|c|c|c|c|}
\hline \multirow{2}{*}{ Composição centesimal (g 100g $\left.{ }^{-1}\right)^{*}$} & \multirow{2}{*}{ GMD } & \multirow{2}{*}{$\mathrm{BC}$} & \multicolumn{2}{|c|}{-------------------Biscoito----------------- } \\
\hline & & & B50 & B100 \\
\hline Umidade & $13,41 \pm 0,07$ & $8,11 \pm 0,01^{b}$ & $7,33 \pm 0,10^{c}$ & $8,43 \pm 0,13^{\mathrm{a}}$ \\
\hline Proteínas & $11,65 \pm 0,43$ & $13,35 \pm 0,37^{\mathrm{a}}$ & $12,59 \pm 0,20^{b}$ & $11,53 \pm 0,11^{\mathrm{c}}$ \\
\hline Lipídios totais & $2,59 \pm 0,13$ & $13,63 \pm 1,04^{\mathrm{a}}$ & $12,78 \pm 0,42^{\mathrm{a}}$ & $13,36 \pm 0,17^{\mathrm{a}}$ \\
\hline Cinzas & $4,36 \pm 0,13$ & $1,62 \pm 0,01^{\mathrm{c}}$ & $1,77 \pm 0,02^{\mathrm{b}}$ & $1,97 \pm 0,04^{\mathrm{a}}$ \\
\hline Fibra alimentar total & $28,90 \pm 1,9$ & $10,60 \pm 0,17^{\mathrm{a}}$ & $9,63 \pm 0,21^{b}$ & $9,80 \pm 0,00^{b}$ \\
\hline Carboidratos & 39,09 & 52,69 & 55,89 & 54,90 \\
\hline Energia (kcal) & 226,27 & 386,82 & 388,97 & 386,01 \\
\hline Minerais (mg $100 \mathrm{~g}^{-1}$ ) & GMD & & & \\
\hline Cálcio & $18,41 \pm 1,54$ & & & \\
\hline Ferro & $5,33 \pm 1,00$ & & & \\
\hline Zinco & $5,07 \pm 0,41$ & & & \\
\hline Aminoácidos essenciais (mg $100 \mathrm{~g}^{-1}$ de proteína) & GMD & Padrão WHO & & \\
\hline Histidina & 35,5 & 16 & & \\
\hline Isoleucina & 39,1 & 31 & & \\
\hline Leucina & 77,3 & 61 & & \\
\hline Lisina & 61,5 & 48 & & \\
\hline Metionina + cistina & 31,3 & 24 & & \\
\hline Fenilalanina + tirosina & 68,5 & 41 & & \\
\hline Treonina & 50,9 & 25 & & \\
\hline Triptofano & 21,0 & 6,6 & & \\
\hline Valina & 51,3 & 40 & & \\
\hline Total & 426,9 & - & & \\
\hline EAE (Ile) & 1,26 & - & & \\
\hline
\end{tabular}

* Resultados apresentados como média \pm desvio-padrão de três replicatas. Médias com letras em comum, entre os biscoitos e na mesma linha, não diferem significativamente entre si (teste de Tukey, 5\% de probabilidade). Siglas definidas na Tabela 1.

${ }^{* * *}$ Valores constituem média de duas repetições. EAE (Escore de Aminoácidos Essenciais): menor relação entre o aminoácido da proteínateste e o respectivo padrão de referência (Ile-isoleucina). Padrão WHO: padrão de necessidade de aminoácidos essenciais de crianças em idade escolar (3 a 10 anos) (WHO, 2007).

escores iguais ou superiores a 6,0 para a avaliação global do biscoito B50 e que cerca de $80 \%$ dos provadores aprovaram a aparência dos biscoitos com GMD (Tabela 3).

Os teores de proteína dos biscoitos (Tabela 2) foram similares aos encontrados em biscoitos doces

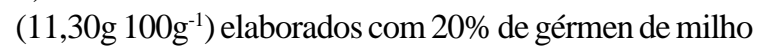
desengordurado (REBOLLEDO et al., 1999), e em biscoitos com farinha mista de fubá $\left(11,74 \mathrm{~g} 100 \mathrm{~g}^{-1}\right)$ (GUILHERME \& JOKL, 2005). Porém, foram superiores aos de produtos similares relatados na literatura, de 3,17g $100 \mathrm{~g}^{-1}$ a $7,76 \mathrm{~g} 100 \mathrm{~g}^{-1}$ (CASTRO et al., 2011; SOARES JÚNIOR et al., 2007; VIEIRA et al., 2010). O teor de proteína relativamente elevado dos biscoitos pode ser explicado pelo maior conteúdo de proteína do GMD (Tabela 2) e do farelo de aveia $\left(9,10 \mathrm{~g} 100 \mathrm{~g}^{-1}\right)$, em relação ao teor proteico da farinha de trigo $\left(2,30 \mathrm{~g} 100 \mathrm{~g}^{-1}\right)$ (NEPA, 2006).

Em relação aos teores de lipídios, os biscoitos testados não diferiram da formulação controle e são compatíveis com os teores de lipídios de biscoitos elaborados a partir de farinhas mistas com fubá (GUILHERME \& JOKL, 2005). Destaca-se que os conteúdos de lipídios dos biscoitos deste estudo foram inferiores aos de biscoitos formulados com gérmen de milho integral (17,8g a 19,5g $100 g^{-1}$ de lipídios) (CASTRO et al., 2011), e aos de biscoitos com 20\% de gérmen de milho desengordurado (21,0g a 21,5g 100g $\mathrm{g}^{-1}$ ) (REBOLLEDO et al., 1999). Esta característica confere vantagens ao GMD, em relação ao gérmen integral (CASTRO et al., 2011), como matéria-prima para elaboração de alimentos com menor teor de lipídios e maior conteúdo de proteínas e, portanto, mais nutritivos e saudáveis. Além disso, os valores energéticos dos cookies (aproximadamente $390 \mathrm{kcal} 100 \mathrm{~g}^{-1}$ ) foram inferiores aos encontrados na literatura para este tipo de produto(GUILHERME \& JOKL, 2005; REBOLLEDO et al., 1999; SOARES JÚNIOR et al., 2007).

Os teores de fibra alimentar dos biscoitos (Tabela 2) foram superiores ao relatado para biscoitos elaborados com alimentos ricos em fibra, como a farinha 
Tabela 3 - Aceitabilidade de biscoitos tipo cookie com relação à avaliação global (sabor, aroma e textura) e aparência.

\begin{tabular}{|c|c|c|c|c|}
\hline \multirow{2}{*}{ Biscoito ${ }^{*}$} & \multicolumn{2}{|c|}{------------------------Avaliação global----------------------- } & \multicolumn{2}{|c|}{----------------------------Aparência--------------------------- } \\
\hline & Média & Aceitação** $\left.^{* *} \%\right)$ & Média & Aceitação $^{* *}(\%)$ \\
\hline $\mathrm{BC}$ & $7,12 \pm 1,31^{\mathrm{a}, \mathrm{b}}$ & 91,7 & $6,69 \pm 1,50^{\mathrm{a}}$ & 79,2 \\
\hline B50 & $7,44 \pm 1,40^{\mathrm{a}}$ & 91,7 & $6,65 \pm 1,51^{\mathrm{a}}$ & 79,2 \\
\hline $\mathrm{B} 100$ & $6,60 \pm 1,62^{\mathrm{b}}$ & 79,2 & $6,58 \pm 1,63^{\mathrm{a}}$ & 81,2 \\
\hline
\end{tabular}

* Siglas definidas na Tabela 1. Valores constituem média \pm desvio-padrão. Médias com letras em comum, na mesma coluna, não diferem significativamente entre si (teste de Tukey, $5 \%$ de probabilidade).

** Aceitação: percentual de provadores que atribuíram escores iguais ou superiores a 6,00.

de amêndoa de baru $\left(1,49 \mathrm{~g} 100 \mathrm{~g}^{-1}\right)$ (SOARES JÚNIOR et al., 2007). Todos os biscoitos do presente estudo podem ser considerados alimentos com alto teor de fibra alimentar, por apresentarem níveis superiores a $6 \mathrm{~g} 100 \mathrm{~g}^{-1}$ (BRASIL, 1998), em decorrência dos conteúdos de fibra alimentar do GMD (Tabela 2) e da amêndoa de baru $\left(11,6 \mathrm{~g} 100 \mathrm{~g}^{-1}\right)$ (FERNANDES et al., 2010).

$\mathrm{O}$ teor de cinzas dos biscoitos elevou conforme o aumento da proporção de GMD na formulação, o que indica que essa fração contém quantidades consideráveis de minerais, conforme já relatado na literatura, com destaque para o ferro e o zinco (NAVES et al., 2011). Os valores de cinzas constatados no presente estudo são compatíveis com os observados para biscoitos enriquecidos com gérmen de milho (CASTRO et al., 2011; REBOLLEDO et al., 1999).

\section{CONCLUSÃO}

O gérmen com pericarpo de milho desengordurado é fonte de proteínas completas em termos de aminoácidos essenciais, além de ser rico em fibra alimentar, ferro e zinco. Os biscoitos tipo cookie formulados com até $15 \%$ de gérmen com pericarpo de milho desengordurado foram bem aceitos sensorialmente, constituem fontes de energia e proteína e contêm altos teores de fibras alimentares. Considerando as características químicas e nutricionais do GMD e a boa aceitação dos biscoitos elaborados com esta matéria-prima, recomenda-se seu uso na alimentação humana, agregando valor a este subproduto do processamento do grão de milho e valor nutricional ao produto elaborado.

\section{REFERÊNCIAS}

ALONZO, N.; HIRS, C.H.W. Automation of sample application in amino acid analyzes. Analytical Biochemistry, Washington, v.23, n.2, p.272-288, 1968. Disponível em: < http://pubs.acs.org/ toc/ancham/83/21>. Acesso em: 21 jun. 2009. doi:10.1016/ 0003-2697(68)90359-X.

AOAC. Association of Official Analytical Chemists. Official methods of analysis. 15.ed. Arlington: AOAC, 1990. 1298 p.
APHA. American Public Health Association. Compendium of methods for the microbiological examination of foods. 4.ed. Washington, 2001. $676 \mathrm{p}$.

BLIGH, E.G.; DYER, W.J. A rapid method of total lipid extraction and purification. Canadian Journal of Biochemistry Physiology, Ottawa, v.37, n.8, p.911-917, 1959.

BRASIL. Agência Nacional de Vigilância Sanitária. Resolução RDC n.12, de 02 de janeiro de 2001: aprova o regulamento técnico sobre os padrões microbiológicos para alimentos. Brasília, DF: 2001. Disponível em: <http://www.anvisa.gov.br/ legis/resol/12_01rdc.htm>. Acesso em: 24 ago. 2010.

BRASIL. Portaria $n^{\circ}$ 27, de 13 de janeiro de 1998: aprova o regulamento técnico referente à informação nutricional complementar (declarações relacionadas ao conteúdo de nutrientes). Disponível em: <http://www.anvisa.gov.br/legis/ portarias/27_98.htm>. Acesso em: 15 jun. 2009.

CASTRO, M.V.L. et al. Fração gérmen com pericarpo de milho na alimentação humana: qualidade nutricional e aplicação tecnológica. Pesquisa Agropecuária Tropical, Goiânia, v.41, n.2, p.213-219, 2011. Disponível em: <http:// www.revistas.ufg.br/index.php/pat>. Acesso em: 26 jun. 2011. doi: $10.5216 /$ pat.v41i2.9659.

CASTRO, M.V.L. et al. Rendimento industrial e composição química de milhos de alta qualidade protéica em relação a híbridos comerciais. Pesquisa Agropecuária Tropical, Goiânia, v.39, n.3, p.233-242, 2009. Disponível em: <http:// www.revistas.ufg.br/index.php/pat>. Acesso em: 14 jan. 2009.

CONAB. Companhia Nacional de Abastecimento. Acompanhamento da safra brasileira - grãos: terceiro levantamento de avaliação da safra 2010/2011 - dezembro 2010dezembro 2010.

FERNANDES, D.C. et al. Nutritional composition and protein value of the baru (Dipteryx alata Vog.) almond from the Brazilian Savanna. Journal of the Science of Food and Agriculture, Oxford, v.90, n.10, p.1650-1655, 2010. Disponível em: <http://onlinelibrary. wiley.com/doi/10.1002/jsfa.3997/ abstract>. Acesso em: 18 nov. 2010. doi: 10.1002/jsfa.3997.

GRASTEN, S.M. et al. Fibers with different solubility characteristics alter similarly the metabolic activity of intestinal microbiota in rats fed cereal brans and inulin. Nutrition Research, New York, v.22, n.12 p.1435-1444, 2002. Disponível em: <http://www.researchgate.net/journal/18790739_Nutrition_research_New_York_NY>. Acesso em: 15 ago. 2009. doi: 10.1016/S0271-5317(02)00473-6. 
GUILHERME, F.F.P.; JOKL, L. Emprego de fubá de melhor qualidade protéica em farinhas mistas para a produção de biscoitos. Ciência e Tecnologia de Alimentos, Campinas, v.25, n.1, p.63-71, 2005. Disponível em: <http://www.scielo.br/ s c i elo.php? s c ri p t = s ci_art text \& pid = S 0101 20612005000100011\&lng $=$ en $\& n r m=i s o \& t \operatorname{lng}=p t>$. Acesso em: 23 set. 2009. doi: 10.1590/S0101-20612005000100011.

HERNANDEZ, B.D et al. Efecto del fraccionamento sobre las características del gérmen de maiz desgrasado. Ciência e Tecnologia de Alimentos, Campinas, v.19, n.1, p.107-112, 1999. Disponível em: <http:/www.scielo.br/scielo.php?script=sci_arttext\&pid=S010120611999000 100019\&lng=en\&nrm=iso\&tlng=es>. Acesso em: 15 set. 2009. doi: 10.1590/S0101-20611999 000100019.

INSTITUTO ADOLFO LUTZ. Métodos físico-químicos para análise de alimentos. 4.ed. Brasília: Ministério da Saúde, 2005. 1018p. (Série A. Normas e Manuais Técnicos).

IOM. Institute of Medicine. Food and Nutrition Board. Dietary reference intakes for vitamin $A$, vitamin $K$, arsenic, boron, chromium, copper, iodine, iron, manganese, molybdenum, nickel, silicon, vanadium, and zinc. Washington: The National Academies, 2001. 773p.

MERRIL, A.L.; WATT, B.K. Energy value of foods: basis and derivation. Washington: United States Departament of Agriculture, 1973. 105p.

NAVES, M.M.V. et al. Corn germ with pericarp in relation to whole corn: nutrient contents, food and protein efficiency and protein digestibility-corrected amino acid score. Ciência e Tecnologia de Alimentos, Campinas, v.31, n.1, p. 264-269, 2011. Disponível em: <http://www.scielo.br/pdf/cta/v31n1/ 40.pdf $>$. Acesso em: 24 jun. 2011. doi: 10.1590/S010120612011000100040.

NEPA - Núcleo de Estudos e Pesquisas em Alimentação. Tabela brasileira de composição de alimentos (TACO). 2.ed. Campinas, 2006. 113p.
PROSKY, L. et al. Determination of insoluble, soluble and total dietary fiber in foods and foods products: interlaboratory study. Journal of the Association of Official Analytical Chemists, Arlington, v.71, n.5, p.1017-1023, 1988.

REBOLLEDO, M.A. et al. Evoluación de galletas dulces enriquecidas con gérmen de maíz y fibra de soya. Archivos Latinoamericanos de Nutrición, Caracas, v.49, n.3, p.253259, 1999.

SOARES JÚNIOR, M.S. et al. Qualidade de biscoitos formulados com diferentes teores de farinha de amêndoa de baru (Dipteryx alata Vog.). Pesquisa Agropecuária Tropical, Goiânia, v.37, n.1, p.51-56, 2007. Disponível em: <http://www.revistas.ufg.br/ index.php/pat>. Acesso em: 21 jun. 2010.

STATSOFT, INC. Statistica: sistema software de análise de dados. Tulsa, 2004. (version 7). Disponível em: <www.statsoft.com>. Acesso em: 05 out. 2009.

STONE, H.; SIDEL, J.L. Affective testing. In: Sensory evaluation pratices. Boca Raton: Academic, 1985. cap.7, p.227-252.

VIEIRA, J.C. et al. Qualidade física e sensorial de biscoitos doces com fécula de mandioca. Ciência Rural, Santa Maria, v.40, n.12, p.2574-2579, 2010. Disponível em: <http:// www.scielo.br/pdf/cr/v40n12/a796cr2909.pdf >. Acesso em: 12 jan. 2011.

WATSON, S.A; RAMSTED, P.E. (Ed.). Corn: chemistry and technology. 4.ed. Saint Paul: American Association of Cereal Chemists, 1999. 605p.

WHO. World Health Organization. Report of a Joint WHO/ FAO/UNU Expert Consultation. Protein and amino acid requirements in human nutrition. Geneva: WHO, 2007. (WHO Technical Report Series, 935). 


\title{
ERRATA
}

Artigo originalmente publicado com erro no nome da cidade na referência FERNANDES, D.C.

\section{Gérmen com pericarpo de milho desengordurado na formulação de biscoitos tipo cookie}

Use of defatted corn germ with pericarp in cookie formulation

\author{
Luciana de Oliveira Froes ${ }^{\mathrm{I}}$ Maria Amélia Oliveira Falqueto ${ }^{\mathrm{II}}$ Maiza Vieira Leão de Castro \\ Maria Margareth Veloso Naves ${ }^{\text {II }}$
}

Para html ou PDF, acesse:

http:/www.scielo.br/scielo.php?script=sci_arttext\&pid=S0103-84782012000400028\&lng=en\&nrm=iso\&tlng=pt

ou

http://www.scielo.br/pdf/cr/v42n4/a9912cr4652.pdf

IPrograma de Pós-graduação e Ciência e Tecnologia de Alimentos, Escola de Agronomia e Engenharia de Alimentos, Universidade Federal de Goiás (UFG), Campus Samambaia, Rodovia Goiânia/Nova Veneza, km 0, 74690-900, Goiânia, GO, Brasil. E-mail: lu@froes.org. "Faculdade de Nutrição, UFG, Goiânia, GO, Brasil 